REG爰梊FM

Borella \& Naime, v(6), no 6, p. 1025 - 1042, 2012.

1025

Rev. Elet. em Gestão, Educação e Tecnologia Ambiental

(e-ISSN: 2236-1170)

\title{
TRANSFORMAR A GESTÃO AMBIENTAL INTEGRADA EM VANTAGEM COMPETITIVA
}

\author{
Ilde Luiz Borella ${ }^{1}$, Roberto Naime ${ }^{2}$ \\ ${ }^{1}$ Professor do curso de Administração e Engenharia \\ Rua Francisco Getúlio Vargas 1130, Caxias do Sul, 95070-560, ilborell@ucs.br \\ Universidade de Caxias do Sul \\ ${ }^{2}$ Professor do Programa de pós-graduação em Qualidade Ambiental \\ RS 239, 2755, Novo Hamburgo, 93.352-000, rnaime@feevale.br \\ Universidade Feevale
}

\begin{abstract}
RESUMO
As exigências mundiais em relação à sustentabilidade ambiental contribuíram para que as empresas entendessem que sua relação com a sociedade não podia ser mais em forma isoladas e ou separada em forma de uma ilha. Este artigo tem por objetivo fazer uma revisão bibliográfica sobre as normas de qualidade (ISO 9000), meio ambiente (ISO 14001), segurança e saúde (OHSAS18000) e responsabilidade social (SA 8000). A integração desta norma é um diferencial competitivo para as empresas. Neste contexto, as empresas passaram a ter práticas somente voltadas para cada das normas e não para uma completa integração dos seus processos. A não integração das normas leva a falhas na gestão destas normas, ficando lacunas na visão sistêmica da empresa. Um sistema integrado de normas pode levar a empresa ter vantagens competitivas de forma a garantir sua sobrevivência para com o futuro.
\end{abstract}

Palavras-chave: gestão, vantagem competitiva, meio ambiente.

\begin{abstract}
The requirements in relation to global environmental sustainability helped companies understand that their relationship with society could not be isolated, or shaped in the formo or a separate island. This articla aims to review the literature on quality standards (ISO 9000), environment (ISO 14001). Health and safety (OHSAS 18000) and social accountability (AS 8000). The integration of this standard is a competitive diferentiatior for companioes. In this contexto, companies now have only focused practice for each standards and not a complete integration of theis processes. Failure to incorporate the reles leads to failures in the management of these standards, leaving gaps in the systems view of the company. Na integrated system of standards can lead the company competitiva avantajes to ensure their survival in the future.
\end{abstract}

Keywords: anagement, competitive advantage, environmental. 


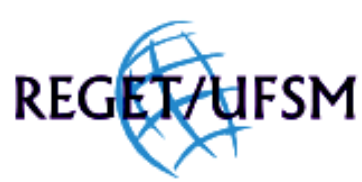

Borella \& Naime, v(6), no 6, p. 1025 - 1042, 2012.

Rev. Elet. em Gestão, Educação e Tecnologia Ambiental

(e-ISSN: 2236-1170)

\section{INTRODUÇÃO}

O planeta esta passando por grandes modificações no que se refere ao meio ambiente. Estas mudanças ocorrem não só com o meio ambiente, mas também com as pessoas. $O$ mercado mundial de produtos está sendo agressivo ao meio ambiente, isto está acontecendo devido ao aumento do numero da população mundial, de sua distribuição desta população no espaço urbano e rural.

O grande desafio para o próximo século para as organizações e enfrentar a concorrência mundial em vários campos da campos da competição, sendo um dos campos o ambiental. No contexto mundial de evolução dos modelos de gestão das empresas de manufatura teve seu inicio no século XX totalmente voltado para o mundo da produtividade, depois veio o mundo dos custos, a inovação e a Engenharia. A entrega passou a ser uma diferencial onde as empresas de hoje estão voltadas para as suas cadeias de valor. Um grande diferencial para o futuro é a proteção ambiental visto que os ecossistemas mundiais esta sob pressão principalmente dos países desenvolvidos.

Diante das profundas mudanças na conjuntura econômica, as empresas vêm sendo pressionadas a alterar seus sistemas internos de gestão e, conseqüentemente, seus processos de produção no sentido de reduzir custos e adequar seus produtos às condições e às necessidades do mercado. É neste cenário que os sistemas de gestão da qualidade, gestão ambiental, gestão da segurança e da gestão da responsabilidade social têm sido cada vez mais objeto da atenção dos gestores, que os têm adotado como forma de gerar vantagem competitiva em relação à concorrência.

Muitas organizações têm buscado mudar sua visão empreendedora, não só olhando para com seus Indicadores Econômicos mas também para os Indicadores Ambientais. Para Santos (2006), a conscientização ambiental empresarial pode ser avaliada à luz de diversos estágios evolutivos, que se constituem a partir da proposição de importantes autores e que formam uma grande pluralidade de níveis de maturidade para a análise da gestão ambiental na organização.

As empresas para serem competitivas devem e terão de desenvolver cada vez mais produtos customizados e ambientalmente sustentáveis. Slack (2002) descreve que a magnitude do impacto ambiental está diretamente relacionada à quantidade da população consumidora e ao impacto ambiental do processo produtivo ou do produto consumido por essa população.

\section{OBJETIVO}

O objetivo principal desse artigo é fazer uma pesquisa bibliográfica sobre o processo de integração das normas de qualidade (ISO 9000), ambiental (ISO 14001), segurança (OHSAS 18001) e responsabilidade social (SA 8000) e descrever como as organizações devem utilizar a integração das normas de qualidade, segurança e ambiental para ter uma vantagem competitiva em Gestão Ambiental.

Os objetivos específicos são: i) descrever as quatro normas e seu impacto nas organizações; ii) identificar os parâmetros iguais das quartas normas; iii) elaborar modelo de integração das normas; iv) utilizar a integração das normas como uma vantagem competitiva para as organizações. 
REGETHFSM

Borella \& Naime, v(6), no 6, p. 1025 - 1042, 2012.

1027

Rev. Elet. em Gestão, Educação e Tecnologia Ambiental

(e-ISSN: 2236-1170)

A situação problemática é que muita das organizações tem as normas implementadas nas organizações, mas sempre de forma não integrada, isto é, a norma de qualidade voltada somente para os clientes da empresa, as normas ambientais para atender a legislação ambiental municipal, estadual e federal a de segurança voltadas para atendimento a legislações e a norma responsabilidade social para atender aos meio onde a empresa está inserida e muitas vezes por solicitação dos seus clientes.

\section{METODOLOGIA}

A metodologia utilizada para elaboração do artigo é uma pesquisa bibliográfica. Para Gil(1999) uma pesquisa bibliográfica deve ter os seguintes critérios: a) o assunto deve ser de interesse do pesquisador; b) o assunto deve apresentar relevância teórica e pratica; c) o assunto deve ser adequado à qualificação do pesquisador; d) deve haver material bibliográfico suficiente e disponível; e) o pesquisador deve dispor de tempo e outras condições de pesquisa. Ele define os seguintes passos para elaboração de uma pesquisa bibliográfica: formulação do problema; elaboração do plano de trabalho; identificação das fontes; localização das fontes e obtenção do material; leitura do material; confecção das fichas; construção lógica do trabalho; redação do texto.

\section{CONCEITOS}

4.1 Gestão Ambiental

Coranza(2003) faz uma análise da evolução da gestão ambiental com as seguintes seqüenciamento:

- década de 70, criação do cargo ligada a área ambiental;

- década de 80, as empresas trabalham nos programas internos de prevenção e proteção ambiental;

- década de 90, inicio de uma integração da gestão ambiental junto aos seus processos organizacionais.

Desta forma Coranza procura mostrar a própria evolução dos conceitos dentro das empresas, juntamente com a própria evolução dos modelos de gestão das organizações.

Barbieri (2007) define o meio ambiente reflete o nosso dia com a interação com ele. 0 prefixo latino Ambi significa ao redor, desta forma meio ambiente mostra a idéia de um lugar que esta em volta do homem sem, contudo, incluí-lo. No sentido geral meio ambiente como condição de existência de vida, envolve a biosfera e estende-se muito além dos limites em que a vida é possivel.

Rohrich e Cunha (2004) definem o termo de gestão ambiental como um conjunto de políticas e estratégias administrativas e operacionais que buscam atender a legislação na área da saúde e a segurança das pessoas e a prevenção do meio ambiente. 
REGETHFSM

Borella \& Naime, v(6), no 6, p. 1025 - 1042, 2012.

Faucheux (1997) identificam dois conjuntos de razões estratégicas que explicam a integração da gestão ambiental pelas empresas: as defensivas e as proativas. Quando se trata das estratégias defensivas, o meio ambiente é encarado como uma restrição suplementar às atividades da empresa. Quando se trata das estratégias proativas, o meio ambiente é encarado como elemento de competitividade extra-custos.

Para Corazza(2003) a integração da gestão ambiental nas organizações devem ocorrer:

- através da integração matricial;

- através do diagnostico do mecanismo de transformação das estruturas das organizações podem influenciar positivamente no seu desempenho ambiental;

- através da permanência do envolvimento efetivo das partes interessadas.

Desta forma a relação do homem com o seu meio ambiente apresenta questões de como ele deve construir as suas condições de vida e quais são os reflexos das opções econômicas adotadas em cada país (Seiffert, 2010).

\subsection{Normas}

Oliveira (2007) define que o processo de certificação de um sistema é o reconhecimento de que ele atende a uma norma de referência e é concedida por uma entidade certificadora credenciada.

O credenciamento das entidades certificadoras está a cargo de um órgão fiscalizador, função exercida no Brasil pelo Instituto Nacional de Metrologia (INMETRO). As normas 9001 (gestão da qualidade) e ISO 14001 (gestão ambiental) contemplam sistemas de controle de processos e envolvem a gestão de suprimentos, recursos humanos, informações, documentos, projeto, produção e distribuição de produtos e serviços, para atender as necessidades dos clientes e da empresa (MAGD; CURRY, 2003).

Essas normas possuem focos similares em relação à racionalização do processo produtivo e incentivam a utilização de várias ferramentas, métodos e práticas para melhoria contínua em comum, além de estarem baseadas no ciclo PDCA (Plan, Do, Check e Action) (CURKOVIC; SROFE; MEINYK, 2005).

A normalização é a atividade que estabelece, em relação a problemas existentes ou potenciais, prescrições destinadas à utilização comum e repetitiva, com vistas à obtenção do grau ótimo em um dado contexto. É um excelente argumento para vendas ao mercado internacional e também um importante instrumento para regular a importação de produtos que não estejam em conformidade com as normas do país comprador.

Porém, no caso das economias em desenvolvimento, os fatores que influenciam a capacidade do país em fazer negócios com os países mais industrializados são, muitas vezes, determinantes para a adoção de práticas de gestão ambiental.

Quando a legislação destes países é mais flexível do que a dos países de origem das empresas multinacionais, estas podem optar por transferir suas operações para filiais nos países em desenvolvimento. Assim, as barreiras tarifárias, as sobretaxas, os códigos empresariais e os selos verdes, que regem o comércio internacional, nesse caso passam a assumir caráter 


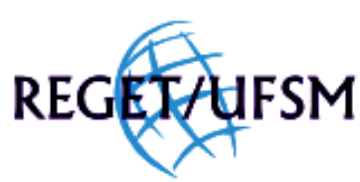

Borella \& Naime, v(6), no 6, p. 1025 - 1042, 2012.

complementar, ao invés de caráter determinante, nos países de economia periférica.

Em países como a Alemanha, por exemplo, a cooperação do empresariado industrial com as políticas de governo tem resultado numa reorganização estrutural da indústria. As autoridades oferecem um prêmio aos produtos e serviços ambientalmente adequados (GRIEFAHN, 1993).

\subsubsection{ISO 9000}

Os modelos de gestão da qualidade evoluíram e cresceram muito nessas últimas décadas. Os Estados Unidos teve o mérito de iniciar esse processo de uns novos processos para com a gestão da qualidade. Em 1940, o surgimento da primeira associação de profissionais da área de qualidade - a Society of Quality Engineers, em 1945 American Society for Quality Control (ASQC) em 1946, atualmente American Society for Quality (ASQ). Pouco depois, em 1950, também seria criada a associação japonesa de cientistas e engenheiros, a Japan Union of Scientists and Engineers (JUSE), com papel importante na área de qualidade (CARVALHO E PALADINI, 2005).

Muitos estudiosos na área da qualidade, hoje chamados de gurus da qualidade, deram suas contribuições de forma sistêmicas aos vários países na busca da qualidade total. São eles: Juran, Feingenbaum, Deming, Crosby, Ishikawa. A abordagem de qualidade nas organizações, passou por várias eras desde um enfoque de inspeção, passando pelo controle, garantia e gestão da qualidade (GARVIN, 1988).

A ISO, cuja sigla significa International Organization for Standardization, é uma entidade não governamental criada em 1947 com sede em Genebra - Suiça. O seu objetivo é promover, no mundo, o desenvolvimento da normalização e atividades relacionadas com a intenção de facilitar o intercâmbio internacional de bens e de serviços e para desenvolver a cooperação nas esferas intelectual, científica, tecnológica e de atividade econômica.

Os membros da ISO (cerca de 90) são os representantes das entidades máximas de normalização nos respectivos países como, por exemplo, ANSI (American National Standards Institute), BSI (British Standards Institute), DIN (Deutsches Institut für Normung) e o INMETRO (Instituto Nacional de Metrologia). O trabalho técnico da ISO é conduzido por Comitês Técnicos (TC's). O estudo sobre a emissão das normas da série ISO 9000, por exemplo, foi feito pelo TC 176 durante o período 1983-1986 (no Brasil, o comitê técnico responsável pelas normas da série NBRISO 9000 é o CB 25, da Associação Brasileira de Normas técnicas - ABNT).

Segundo Franceschini (2006), no final dos anos 70, vários países estavam criando um padrão de normalização interno básico para aplicação em setores específicos que necessitavam de alguns requisitos mínimos para garantir a qualidade de seus produtos. A International Organization for Standardization interessou-se pela regulamentação destas atividades em diferentes setores industriais e formulou a primeira série de normas ISO 9000, em 1987.

O modelo de um sistema de gestão da qualidade, baseado em uma abordagem de processo, conforme mostrado na figura1. Esta ilustração mostra que os clientes desempenham um papel significativo na definição dos requisitos como entradas. O monitoramento da satisfação do cliente requer a avaliação de informações relativas à percepção do cliente sobre se a organização atendeu aos requisitos do cliente. abrange todos os requisitos da Norma, mas não apresenta processos em um nível detalhado (Norma ISO9001, 2008).

A norma ISO 9001 mostra como deve ser elaborado um modelo de gestão e tem como objetivo a padronização dos seus processos. Tem como vantagem de sua utilização devido ao fato 
de ser universal, isto é, tal sua validação em todos os cinco continentes. No caso de sua implantação na empresa, está recebe um certificado o qual tem validação em todos os continentes.

\subsubsection{ISO 14001}

Diante das profundas mudanças na conjuntura econômica, as empresas vêm sendo pressionadas a alterar seus sistemas internos de gestão e, conseqüentemente, seus processos de produção no sentido de reduzir custos e adequar seus produtos às condições e necessidades do mercado. É neste cenário que os sistemas de gestão da qualidade e gestão ambiental têm sido cada vez mais objeto da atenção dos gestores, que os têm adotado como forma de gerar vantagem em relação à concorrência. Os certificados mais procurados são além da ISO 14000(VINHA 2003).

Por essa razão, há uma procura de empresas que querem diferenciar-se e, portanto, participam da corrida à certificação que agrega valor ao produto, pois representa um selo de confiança no sistema de gestão implementado pelas empresas.

A norma NBR ISO 14001 estabelece requisitos para gerenciamento de sistemas de gestão ambiental (SGAs) sem definir a forma e o grau que eles devem ter ou alcançar, permitindo, portanto, que as empresas desenvolvam suas próprias soluções para o atendimento das exigências da norma (NORMA, ISO 14001).

De acordo com a ISO 14001:2008 sistema de gestão ambiental é a parte do sistema de gestão global que inclui estrutura organizacional, atividades de planejamento, responsabilidades, práticas, procedimentos, processos e recursos para desenvolver, implementar, atingir, analisar criticamente e manter a política ambiental. A proteção do meio ambiente não pode ser ignorada no dia a dia das empresas, pois sem tal preocupação, elas terão sua viabilidade econômica e a própria competitividade comprometida. "Acompanhar o crescimento das reivindicações ambientais e a sua transformação em novas ideologias e valores sociais que se consubstanciam em mudanças na legislação e em regulamentações mais severas é tarefa muito importante para a sobrevivência e lucratividade da empresa no longo prazo.

Essa concepção se refletiu nas organizações de todos os portes e setores. Refutar essa concepção tem sido um processo lento, tendo-se chegado, em alguns países, na incorporação da visão de stakeholders nas novas estratégias de desenvolvimento.

O controle dos riscos ambientais do crescimento econômico assume contornos bem específicos nos países em desenvolvimento. O Brasil dispõe de legislação ambiental bastante moderna. A fiscalização, porém, é insuficiente. Babakri (2004) confere um caráter universal, pois, dessa forma, podem ser adaptados por empresas de qualquer região e de todos os portes.

Para o caso específico da normalização ambiental, foi criado em 1994 o Grupo de Apoio à Normalização Ambiental (GANA), resultante de iniciativa de 36 empresas, além de associações, universidades e entidades representativas de setores econômicos e técnicos considerados importantes no país.

A GANA contribuiu para a elaboração da série ISO 14000, apresentando as particularidades relacionadas ao meio ambiente de um país tropical e de uma economia em desenvolvimento. Nas reuniões anuais do Comitê Técnico de Gestão Ambiental da ISO, o Brasil esteve sempre entre as três maiores comitivas. Mais tarde, a GANA foi substituída pelo Comitê Brasileiro de Gestão 
REG或

Borella \& Naime, v(6), no 6, p. 1025 - 1042, 2012.

1031

Rev. Elet. em Gestão, Educação e Tecnologia Ambiental

(e-ISSN: 2236-1170)

Ambiental, que avalia as revisões das normas com novas propostas.

A escolha de opções tecnológicas das empresas podem ser as mais diversas. A escolha daquela que resulta em desenvolvimento sustentável depende de fatores tais como: a escassez de recursos naturais, mercados mais competitivos, pressão da sociedade civil, existência de mecanismos de fiscalização e, finalmente, o próprio custo financeiro para implantação e certificação da norma ISO 14000.

Para a Norma ISO 14001 tem como objetivo a aplicação de requisitos a um sistema da gestão ambiental, permitindo a uma organização desenvolver e programar uma política e objetivos que levem em conta os requisitos legais e outros requisitos por ela subscritos e informações referentes aos aspectos ambientais significativos. Aplica-se aos aspectos ambientais que a organização identifica como aquele que possa controlar e aqueles que possam influenciar. Em si, esta Norma não estabelece critérios específicos de desempenho ambiental (Norma ISO 14001, 2010):

a) estabelecer, implementar, manter e aprimorar um sistema da gestão ambiental;

b) assegurar-se da conformidade com sua política ambiental definida;

c) demonstrar conformidade com esta Norma ao fazer uma auto-avaliação ou auto declaração ou buscar confirmação de sua conformidade por partes que tenham interesse na organização, tais como clientes, ou buscar confirmação de sua autodeclaração por meio de uma organização externa, ou buscar certificação/registro de seu sistema da gestão ambiental por uma organização externa.

Todos os requisitos da Norma ISO14001 devem ser incorporados em qualquer sistema da gestão ambiental. A extensão da aplicação dependerá de fatores tais como a política ambiental da organização, a natureza de suas atividades, produtos e serviços, o local e as condições nas qual o sistema funciona.

\subsubsection{OCCUPATIONAL HEALTH AND SAFETY ASSESSENT SEREIS- OHSAS 18000}

Com a revolução industrial o homem passa por fenômenos sem precedentes que mudará completamente o processo de produção e suas relações com o trabalho. O trabalho especializado e repetitivo deu ensejo a uma série de problemas para o trabalhador, como distúrbios ergonômicos, psicológicos, mutilações e até mesmo a morte. No inicio do século XIX, tem-se os primeiros médicos em fábricas, e são criadas as primeiras leis para proteger o trabalhador. Nesse período tem inicio a atuação dos sindicatos, com o objetivo de viabilizar o controle social necessário à melhoria das condições do ambiente de trabalho (SEIFFERT, 2008).

Em 1919 surgiu a Organização Internacional do Trabalho (OIT), que em suas primeiras reuniões se discutia as doenças profissionais. Nesse período foi criado o conceito e o desenvolvimento da Higiene Industrial e de Ergonomia, no âmbito da Engenharia de Segurança Ocupacional.

Em 1950, com a interface da OIT e da Organização Mundial da Saúde (OMS), surge o conceito de Saúde Ocupacional, como a ciência que visa à promoção e manutenção do mais alto grau de bem-estar físico, social e mental dos trabalhadores (COLACIOPPO, 2004). 
REGEIAfSM

Borella \& Naime, v(6), no 6, p. 1025 - 1042, 2012.

1032

Rev. Elet. em Gestão, Educação e Tecnologia Ambiental

(e-ISSN: 2236-1170)

O direito do ser humano a um ambiente de trabalho saudável e a qualidade ambiental é estabelecido pela Constituição Brasileira desde 1988, a qual em seu artigo 7: ...são direitos dos trabalhadores urbanos e rurais além de outros que visem à melhoria da sua condição social..., redução dos riscos inerentes ao trabalho, por meio de normas de saúde, higiene e segurança. Já o artigo 225: todos têm direito ao meio ambiente ecologicamente equilibrado, bem de uso comum do povo e essencial à sadia qualidade de vida, impondo-se ao Poder Público e à coletividade o dever de defendê-lo e preservá-lo para os presentes e futuras gerações (SEIFFERT, 2008).

Somente em 1994 surge a normalização através das Portarias 24 e 25 do Ministério do Trabalho criando os Programas de Prevenção do Risco Ambiental (PPRA) e o Programa de Controle Médico de Saúde Ocupacional (PCMSO), juntamente as Normas Regulamentadoras NR 9 e NR 7, que entraram vigor no ano de 1995.

A norma britânica BS 8800, que continua válida, motivou diversas entidades normativas a elaborar em 1988 um conjunto de normas intituladas de Occupational Health and Safety Assessment Series - OHSAS, visando à realização de auditorias e à certificação de programas de gestão de segurança, saúde e meio ambiente. As organizações não atuam isoladamente, ou seja, diversas partes podem ter um interesse legítimo na implantação de um sistema de gestão. Essas partes são os empregados, consumidores, clientes, fornecedores, comunidade, acionistas, empreiteiros, assim como as agências governamentais encarregadas de zelar pelo cumprimento dos regulamentos e leis (QUELHAS, 2006).

O surgimento da norma OHSAS (Ocupacional Health and Safety Assessment Series), ocorre em 1996, por um grupo de organismos certificadores (BSI, BVQI, DNV, Lloyds Register, SGS) e de entidades nacionais de normalização da Irlanda, Austrália, África do Sul, Espanha e Malásia, em reunião que ocorreu na Inglaterra.

A busca para a sustentabilidade das organizações é necessária possuir garantia de que suas operações não irão provocar ações futuras no que se refere a suas práticas em relação aos trabalhadores (passivos trabalhistas) e ao meio ambiente (passivos ambientais), quanto à continuidade de disponibilidade de bons fornecedores, quanto à construção de imagem positiva junto à opinião pública e quanto ao cumprimento da legislação e ao recolhimento de taxas e impostos (ARANTES, 2005).

A norma passou a ser chamada de norma da segurança OHSAS 18001, que tem como objetivo das empresas terem um padrão de referência com aceitação internacional no que se refere ao risco do surgimento de passivos trabalhistas. Ela estabelece a eliminação e a redução dos riscos aos funcionários e outras partes interessadas, pertencentes à organização. Conforme a Norma 18001 são os seguintes requisitos:

- assegurar aos clientes o comprometimento com a gestão do SSO (Segurança e Saúde Ocupacional);

- manter boas relações com trabalhadores e sindicatos;

- fortalecer a imagem da empresa junto aos seus clientes diretos ou indiretos;

- melhoria da imagem pública da empresa;

- reduzir acidentes que impliquem em responsabilidade civil;

- maior motivação dos funcionários;

- maior produtividade relacionada à baixa taxa de absenteísmo; 
REGEXfHFS

Borella \& Naime, v(6), no 6, p. 1025 - 1042, 2012.

1033

Rev. Elet. em Gestão, Educação e Tecnologia Ambiental

(e-ISSN: 2236-1170)

- maior facilidade de acesso a financiamentos;

- possibilidade de obtenção de seguros patrimoniais a custos mais reduzidos;

- incorporação de forma sistematizada à cultura da organização do Programa de Prevenção

de

- Riscos Ambientais (PPRA) e Programa de Controle Médico de Saúde Ocupacional (PCMSO) Regulamentados pelo Ministério do Trabalho;

- melhorar as relações entre organização e os órgãos públicos de fiscalização trabalhista;

- implantar um processo sistematizado de análise de riscos e avaliação de perigos relacionados

- a incidentes de saúde e segurança ocupacional e ambiental;

- permitir compartilhar experiências sobre prevenção de riscos trabalhistas sobre uma base normativa comum;

- evidenciar o funcionamento do sistema de higiene e de segurança da empresa;

- eliminar/minimizar os riscos de acidentes, garantindo a proteção dos colaboradores da empresa, com conseqüente redução dos riscos laborais;

- instituir a adoção de boas práticas de higiene, segurança e saúde no trabalho, tanto por parte da empresa como pelos colaboradores;

- cumprir os requisitos legais, contratuais, sociais e financeiros de segurança e higiene do trabalho;

- adotar um sistema de gestão de segurança e higiene no trabalho que permita cumprir os requisitos legais.

Cada vez mais, destacam-se as preocupações do governo, empresários e sindicatos em melhorar a segurança, a saúde e as condições do meio ambiente de trabalho. Para isto, é necessário um planejamento que permita a participação da alta administração e dos empregados para encontrar as soluções práticas e economicamente viáveis. A melhoria da segurança, da saúde e do meio ambiente de trabalho, além de aumentar a produtividade, diminui o custo do produto final, pois diminui as interrupções no processo, o absenteísmo e os acidentes e/ou doenças ocupacionais. Os aspectos preventivos envolvidos na segurança do trabalho buscam minimizar os riscos e as condições inadequadas e incorporar a melhoria contínua das condições de trabalho, introduzindo requisitos mínimos de segurança cada vez mais rígidos (ARANTES, 2005).

\subsubsection{SA 8000 (Social Aconntability)}

Grajew (2001) menciona que a falta de estabilidade política e social é uma ameaça à sociedade e aos negócios. Isso tem contribuído para a mudança do papel das empresas, que, até pouco tempo, se preocupavam em oferecer produtos e serviços aos clientes e alguns empresários praticavam apenas a filantropia individual. Mais tarde, somente algumas empresas passaram a desenvolver projetos sociais nas comunidades e outras vieram a agregar uma gestão de responsabilidade social a sua corporação. 


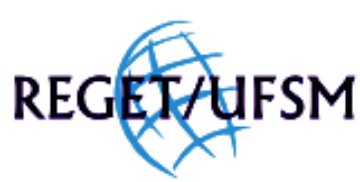

Borella \& Naime, v(6), no 6, p. 1025 - 1042, 2012.

Antunes (2001) relata que, no século 19, Robert Owen, em sua fábrica de fios de algodão, na Escócia, já desenvolvia ações inimagináveis para a época, de plena eflorescência da revolução industrial, como prover um digno ambiente de trabalho e incentivo à educação. Ele comenta que nos anos 80, as Organizações Não-Governamentais que trabalhavam com aspectos políticos passaram a trabalhar com aspectos sociais. E que, nos anos 90 , cresceu muito a filantropia corporativa.

A SA 8000 é um princípio ético balizador das ações e relações da empresa com os públicos com os quais ela interage. Ela é baseada nas normas da Organização Internacional do Trabalho, na Declaração Universal dos Direitos Humanos e na Declaração Universal dos Direitos da Criança (SA 8000).

Apesar de esse histórico trazer datas longínquas da existência de ações sociais, o assunto responsabilidade social ainda é enquadrado como novo e, apenas em 1997, surge a Norma SA 8000. O motivo que deu o maior impulso para a elaboração do padrão SA, concluído em 1997, foi à denúncia de utilização de mão-de-obra infantil e escrava na indústria chinesa de brinquedos, maior fornecedora das redes americanas de varejo. Surgiu como uma resposta à pressão do mercado consumidor sobre empresas que ignoram o descaso de seus fornecedores em relação às condições de trabalho oferecidas em suas fábricas (ARNT, 2001).

O surgimento da SA 8000 é a norma que comprova a responsabilidade social de uma empresa. Lançada pelo Council of Economic Priorities Accreditation Agency (Órgão Credenciador do Conselho e Prioridades Econômicas - CEPAA), em outubro de 1997, a norma SA 8000 é uma iniciativa coletiva que visa a reunir códigos de conduta cada vez mais fragmentados e oferecer definições claras de termos na área de direitos do trabalhador, incluindo trabalho forçado, saúde e segurança entre outros (MCINTOSH, 2001).

O processo de evolução na SA 8000 teve a contribuição de Organizações NãoGovernamentais, como o Conselho de Prioridades Econômicas, empresas e sindicados que estavam elaborando seus critérios para a obtenção de recursos. Isso acarretou o desenvolvimento de critérios para medir o desempenho das empresas em nível mundial. A SA 8000 constitui um código de responsabilidade social perante terceiros que pode ser aplicado internacionalmente a todos os setores comerciais para se avaliar se empresas ou outras organizações estão cumprindo as normas básicas de práticas de trabalho e direitos humanos e, por fim, a uma gama mais ampla de questões. Como posição inicial de auditoria, a SA 8000 se preocupa apenas com as questões essenciais de direitos humanos e as questões associadas à saúde e à segurança e oportunidades iguais (MCINTOSH, 2001).

A SA 8000, entre outros aspectos, verifica as condições de trabalho em toda a cadeia produtiva. Esse certificado abriu caminhos para o surgimento de políticas de Responsabilidade Social Corporativa nas empresas, obrigando-as ao empenho de envolverem seus stakeholders e manterem relacionamentos produtivos de longo prazo.

Vinha (2003) ressalta que hoje agregam a esses stakeholders as vítimas, reais potenciais, da poluição ambiental. Com base nesse princípio, Vinha explica que o principal desafio das organizações é aprender a lidar com os anseios e as expectativas das populações locais, com a pressão do movimento ambientalista e com o poder de barganha dos órgãos públicos, principalmente quando essas organizações, de pequeno, médio ou grande porte, operam em áreas ambientalmente sensíveis. 
REGEIAFSM

Borella \& Naime, v(6), no 6, p. 1025 - 1042, 2012.

1035

Rev. Elet. em Gestão, Educação e Tecnologia Ambiental

(e-ISSN: 2236-1170)

Para Oliveira (2004), a norma funciona como um princípio ético balizador das ações e relações da empresa com os públicos com as quais ela interage - funcionários, consumidores, fornecedores e comunidade. Seu principal objetivo é a busca de valor para todos os elos dessa cadeia. A certificação do sistema de responsabilidade social com base na norma SA 8000 por uma entidade independente, com reconhecimento internacional, dá credibilidade ao trabalho da empresa.

Segundo o Social Acconntability Internacional (2009) em dezembro de 2009 havia 2103 empresas com a certificação, envolvendo 63 países, sendo os maiores pais a Itália, seguindo pela Índia, China, Paquistão e em quinto lugar o Brasil.

\section{Integração das Normas}

Diante das profundas mudanças na conjuntura econômica, as empresas vêm sendo pressionadas a alterar seus sistemas internos de gestão e, consequentemente, seus processos de produção no sentido de reduzir custos e adequar seus produtos às condições e necessidades do mercado. É neste cenário que os sistemas de gestão da qualidade, gestão ambiental, gestão da segurança e a gestão da responsabilidade social têm sido cada vez mais objeto da atenção dos gestores, que os têm adotado como forma de gerar vantagem em relação à concorrência.

As empresas, nos dias atuais, buscam atender as exigências dos clientes, através da legislação ambiental e de seus modelos de gestão, sendo que cada para um público separado e não em formas de estar totalmente integrado.

A preservação do meio ambiente é um aspecto que vem atraindo atenção no mundo inteiro, seja pela crescente conscientização ambiental e pela preocupação com gerações futuras, ou por aspectos tais como: pressões de consumidores, pressões de sindicatos, partidos, opinião pública, seguradoras, partidos verdes, organizações não governamentais, etc. Por outro lado, a conscientização sobre a qualidade de vida e devido aos grandes acidentes ((Bocal, Chernobyl, Espn, Petrobrás, Ilhas Galápagos, BP (2010)), podem levar há um conseqüente crescimento do efeito estufa e diminuição da camada de ozônio, tornaram-se aspectos que também atraem a atenção do mundo devido à preocupação com aspectos da segurança e saúde.

A associação entre produção, qualidade, meio ambiente e segurança é muito importante para a sobrevivência da empresa no longo prazo. Percebe-se a introdução de outra questão importante na quais as organizações devem estar atentas, a preocupação com a saúde e segurança do trabalhador (OLIVEIRA, 2004).

Segundo Sun (2000), um sistema de gestão é uma ferramenta que influencia de maneira sistemática, integrada e consistente as perspectivas que envolvem todos e tudo em uma organização, oferecendo um genérico conceito para melhoria das performances.

Um sistema de gestão é a interação de partes, recursos, atividades e processos com determinado objetivo comum. Diferentemente, o processo é a transformação de entradas, que, após processamento, são transformadas em saídas: produto, serviços, informação, etc. (CASTRO; OLIVEIRA, 2007).

A integração das Normas ISO, OHSAS e SA é possível, pois todas as quatro normas tem procedimentos e instruções e estão totalmente alinhados, conforme mostrado na Figura 1. 
A figura 1 apresenta através de uma esquema como é possível fazer a integração das normas, isto é, podas partem de três princípios:
1) definição da Política;
2) modelo de gestão;
3) Procedimentos do seu processo internos.

A integração das quatro normas, como mostrado na Figura 2, mostra que é totalmente viável, pois a empresa tem seus processos (produção, qualidade, financeiros, ambiental, segurança, etc.) e todos eles podem estar integrados. A diferença entre as normas está somente no que refere as partes interessadas, sendo que a norma da qualidade está voltada para os clientes, a ambiental para os órgãos de controle, a de segurança voltada para o Ministério do Trabalho e Social voltada para a comunidade onde a empresa está inserida.

A tabela 1 mostra as relações entre as normas. De uma forma sistematizada, todas as normas se relacionam. Foi dividida em dez itens: requisitos, política, forma de atender os clientes, atender a legislação, melhoria continua, público interno, registro de dados, atendimentos a não conformidades, funcionamento da norma e análise crítica da alta administração.

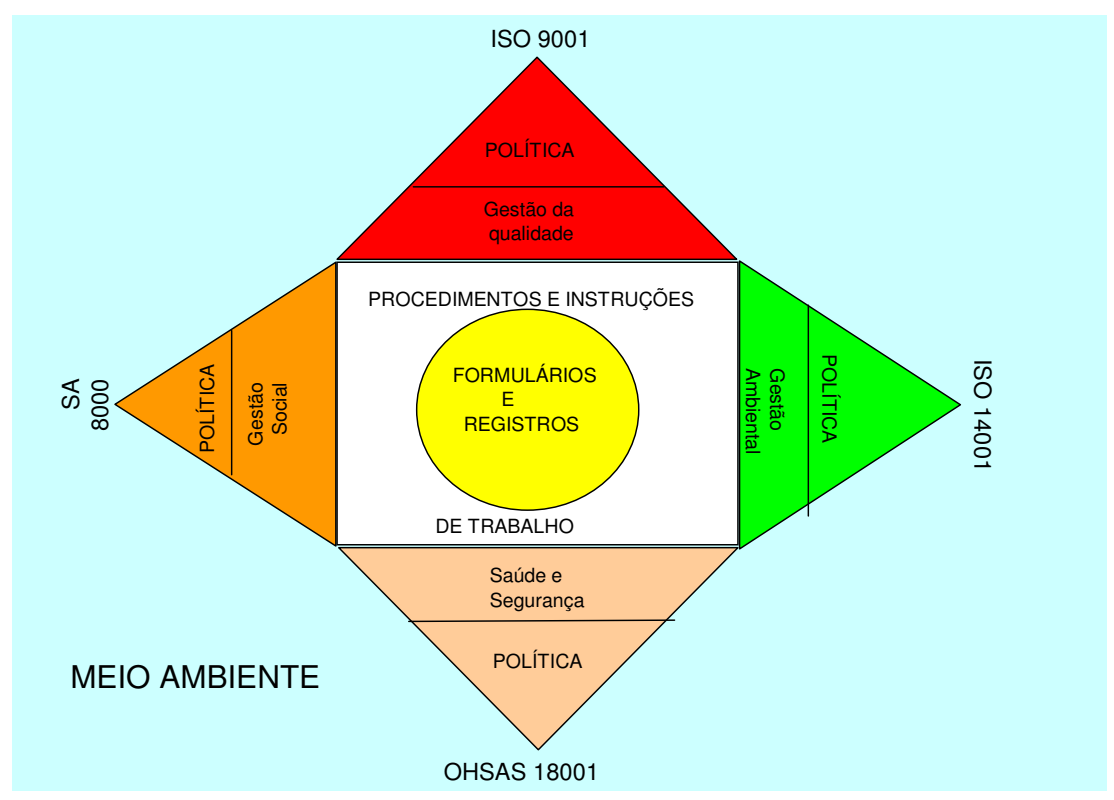

Figura 1 - Integração das Normas

Fonte: elaborado pelos autores

A tabela 1 mostra as relações entre as normas. De uma forma sistematizada, todas as normas se relacionam. Foi dividida em dez itens: requisitos, política, forma de atender os clientes, atender a legislação, melhoria continua, público interno, registro de dados, atendimentos a não conformidades, funcionamento da norma e análise crítica da alta administração.

O processo da integração das normas procura mostrar que elas se fundamentam em busca 
de Melhoria Contínua E PDCA.

O Modelo PDCA (Plan-Do-Check-Act) é obrigatório nas quatro normas. O modelo PDCA pode ser descrito resumidamente como segue (NBR ISO 9001-2008):

- Plan (planejar): estabelecer os objetivos e processos necessários para gerar resultados de acordo com os requisitos do cliente e com as políticas da organização;

- Do (fazer): implementar os processos;

- Check (checar): monitorar e medir processos e produtos em relação às políticas, aos objetivos e aos requisitos para o produto e relatar os resultados;

- Act (agir): executar ações para promover continuamente a melhoria do desempenho.

A busca da integração das normas ISO, OHSAS e SA é um fato novo, pois poucas empresas no Brasil tem seus processos integrado. A base para dar sustentação é o fato mostrado na tabela 2 , onde mostra o número de empresas certificadas em cada uma das normas no Brasil.

Tabela 1 - Relação entre os requisitos das Normas

\begin{tabular}{|c|c|c|c|c|}
\hline & ISO 14001 & ISO 9001 & OHSAS 18001 & S.A 8000 \\
\hline Requisitos & $\begin{array}{l}\text { Requesitos do Sistema } \\
\text { de Gestão Ambiental }\end{array}$ & $\begin{array}{l}\text { Sistema de Gestão da } \\
\text { Qualidade }\end{array}$ & $\begin{array}{l}\text { Elementos do Sistema } \\
\text { de Gestão da SSO }\end{array}$ & $\begin{array}{l}\text { Sistema de Gestão da } \\
\text { Responsabilidade } \\
\text { Social }\end{array}$ \\
\hline Política & Política Ambiental & Política da Qualidade & Política da SSO & $\begin{array}{l}\text { Atender os requisitos } \\
\text { da OIT }\end{array}$ \\
\hline $\begin{array}{l}\text { Forma de atender } \\
\text { os clientes }\end{array}$ & $\begin{array}{l}\text { Aspectos e Impactos } \\
\text { Ambientais }\end{array}$ & $\begin{array}{l}\text { Determinação dos } \\
\text { requisitos dos clientes } \\
\text { relacionados a } \\
\text { produtos e processos }\end{array}$ & $\begin{array}{l}\text { Identificação dos } \\
\text { perigos e avaliação e } \\
\text { controle dos riscos }\end{array}$ & $\begin{array}{l}\text { Aspectos e Impactos } \\
\text { no Homem }\end{array}$ \\
\hline $\begin{array}{l}\text { atender } \\
\text { legislação }\end{array}$ & $\begin{array}{l}\text { Requisitos legais e a } \\
\text { Licença de Operação }\end{array}$ & $\begin{array}{l}\text { Atendimento aos } \\
\text { requisitos do cliente }\end{array}$ & Requisitos legais & $\begin{array}{l}\text { Atender requisitos de } \\
\text { responsabilidade } \\
\text { Social }\end{array}$ \\
\hline $\begin{array}{l}\text { Melhoria } \\
\text { Continua }\end{array}$ & $\begin{array}{l}\text { Programa e Melhoria } \\
\text { Continua }\end{array}$ & $\begin{array}{l}\text { Programa de Melhoria } \\
\text { Continua }\end{array}$ & $\begin{array}{l}\text { Programa de Melhoria } \\
\text { Continua }\end{array}$ & $\begin{array}{l}\text { Programa de Melhoria } \\
\text { Continua }\end{array}$ \\
\hline Público Interno & $\begin{array}{l}\text { Treinamento, } \\
\text { conscientização } \\
\text { competências }\end{array}$ & $\begin{array}{l}\text { Treinamento, } \\
\text { conscientização } \\
\text { competências }\end{array}$ & $\begin{array}{l}\text { Treinamento, } \\
\text { conscientização } \\
\text { competências }\end{array}$ & $\begin{array}{l}\text { Treinamento, } \\
\text { conscientização } \\
\text { competências }\end{array}$ \\
\hline
\end{tabular}




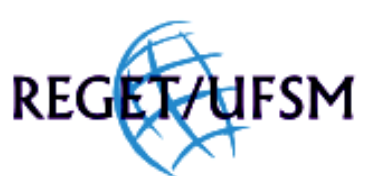

Borella \& Naime, v(6), no 6, p. 1025 - 1042, 2012.

Rev. Elet. em Gestão, Educação e Tecnologia Ambiental

(e-ISSN: 2236-1170)

\begin{tabular}{|c|c|c|c|c|}
\hline $\begin{array}{l}\text { Registro } \\
\text { dados }\end{array}$ & $\begin{array}{lll}\text { Documentação } & & \text { e } \\
\text { controle } & & \text { de } \\
\text { documentos } & \text { e } & \text { de } \\
\text { dados } & & \end{array}$ & $\begin{array}{llr}\text { Documentação } & & \text { e } \\
\text { controle } & & \text { de } \\
\text { documentos } & \text { e } & \text { de } \\
\text { dados } & & \end{array}$ & $\begin{array}{llr}\text { Documentação } & & \text { e } \\
\text { controle } & & \text { de } \\
\text { documentos } & \text { e } & \text { de } \\
\text { dados } & & \end{array}$ & 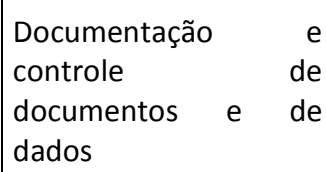 \\
\hline $\begin{array}{l}\text { Atendimento a } \\
\text { não } \\
\text { conformidades }\end{array}$ & $\begin{array}{l}\text { Preparação } \\
\text { atendimento } \\
\text { emergências }\end{array}$ & $\begin{array}{lr}\text { Sistema de } \\
\text { Rastreavilidade } \\
\text { controle do produto }\end{array}$ & $\begin{array}{l}\text { Preparação } \\
\text { atendimento } \\
\text { emergências }\end{array}$ & $\begin{array}{l}\text { Pesquisa de } \\
\text { Satisfaçaõcom todos as } \\
\text { partes interessadas }\end{array}$ \\
\hline $\begin{array}{l}\text { Funcionamento } \\
\text { da a norma }\end{array}$ & $\begin{array}{l}\text { Não-conformidades e } \\
\text { ações corretivas e } \\
\text { preventivas }\end{array}$ & $\begin{array}{l}\text { Não-conformidades e } \\
\text { ações corretivas e } \\
\text { preventivas }\end{array}$ & $\begin{array}{l}\text { Acidentes, incidentes, } \\
\text { não-conformidades e } \\
\text { ações corretivas e } \\
\text { preventivas }\end{array}$ & $\begin{array}{lr}\text { Tratando } & \text { das } \\
\text { preocupações, ações } & \text { erretivas } \\
\text { corres } & \text { e } \\
\text { comunicação externa }\end{array}$ \\
\hline $\begin{array}{l}\text { Análise Crítica da } \\
\text { alta } \\
\text { administração }\end{array}$ & $\begin{array}{l}\text { Análise Crítica pela } \\
\text { Alta Administração }\end{array}$ & $\begin{array}{l}\text { Análise Crítica pela } \\
\text { Alta Administração }\end{array}$ & $\begin{array}{l}\text { Análise Crítica pela } \\
\text { Alta Administração }\end{array}$ & $\begin{array}{l}\text { Análise Crítica pela } \\
\text { Alta Administração }\end{array}$ \\
\hline
\end{tabular}

Fonte: Elaborado pelos autores

Para a Norma AS 8000 as informações são muito poucas no Brasil. Segundo Social Accountability International (SAI), (março, 2010), temos 2.151 empresas nos cinco continentes, somente que ela participa somente em 60 países. 0 Brasil tem 76 empresas com certificação e o Rio Grande do Sul com 12 empresas.

Os números de empresas certificadas na ISO 9001 havia 455 empresas certificadas para um número de aproximadamente 29.000 em 2010. Da Mesma forma as empresas certificadas com ISO 14001 hoje com 4500 empresas e OHSAS com aproximadamente 2000 empresas.

Fazendo-se uma análise destes dados, em que no mundo somente 76 empresas são certificadas com a SA 8000, é difícil termos empresas que tenha de uma forma sistematizada a interação das normas. Geralmente o que ocorre com as organizações é ter as quatro normas não integradas, onde cada uma das norma é atendida conforme descrito na Tabela 1.

\section{VANTAGEM COMPETITIVA AMBIENTAL}

Kaplan e Norton (2004) definem um novo ambiente organizacional. As empresas estão baseadas em novos conjuntos de premissas: processos inter-funcionais, ligação com clientes e fornecedores, clientes preferenciais, escala global, inovação, trabalho e conhecimento, gestão da qualidade total, gestão de custos voltadas para as atividades. A falha desse modelo é a falta da uma visão ambiental. 
REGEXfIFSM

Borella \& Naime, v(6), no 6, p. 1025 - 1042, 2012.

Porter (1990) define como as empresas com vantagem competitiva são aquelas que o resultado da empresa de realizar o conjunto de atividades necessárias para obter mais baixo um custo mais baixo, que o dos concorrentes, ou de organizar essas atividades de uma forma única, capaz de gerar um valor diferenciado para os compradores. Nesse cenário, Porter define como estratégia o papel reservado a proteger a empresa da ação das forças competitivas.

No entanto, para que se possa explorar adequadamente este potencial, é necessário, antes de tudo, garantir à manutenção e disponibilidade destes recursos no meio ambiente, sendo assim fundamental a implementação de mecanismos de conservação ambiental (por conservação, entende-se o uso racional dos recursos, de modo a evitar riscos de extinção) e modelos de desenvolvimento sustentáveis.

Muitas empresas têm visto neste cenário uma oportunidade de negócio. A incorporação de modelos sustentáveis de uso e exploração dos recursos passa a ser visto como um diferencial capaz de gerar vantagens competitivas.

Deste modo, estas empresas têm procurado integrar os princípios e práticas do desenvolvimento sustentável em seu contexto de negócio: as dimensões econômica, social e ambiental da sustentabilidade no aproveitamento do potencial da biodiversidade.

Este tipo de estratégia requer investimentos e capacitação em inovação, seja esta tecnológica ou organizacional, interna ou em parceria. É neste contexto que se inserem, por exemplo, as atuais estratégias de algumas empresas nacionais atuantes em diferentes setores, como extratos naturais, cosméticos, perfumaria e higiene pessoal, as quais vêm procurando acompanhar e aproveitar o uso econômico da biodiversidade no desenvolvimento de novas trajetórias abertas por este mercado.

A exploração da questão ambiental tem se baseado no aproveitamento de fatores competitivos como ativos intangíveis (notadamente marca) e comerciais (marketing, canais de distribuição), diversificação de mercado, diferenciação de produtos e, não menos importante.

As diferentes formas de organizar a produção e incorporar novos conceitos e paradigmas têm impactos significativos sobre a capacidade de reação a mudanças no ambiente competitivo, identificação de oportunidades de lucro e ação estratégica.

A incorporação da variável ambiental e do conceito de desenvolvimento sustentável requer mudanças organizacionais, adaptação e/ou substituição de processos produtivos, adequação e/ou antecipação a normas ambientais e de segurança.

Todo este processo acarreta custos para a empresa e exige estruturas de gerenciamento adequado para programar a nova estratégia. As estratégias são a bases da competitividade e podem ser definidas como o conjunto de gastos em gestão, recursos humanos, produção e inovação, segmentação e diferenciação que visam ampliar e renovar a capacitação de empresas nas dimensões exigidas pelos padrões de concorrência vigentes nos mercados de que participam (FERRAZ, 1996).

Nesse sentido, as estratégias estão condicionadas pelo ambiente competitivo, no qual são definidos os padrões de concorrência e pela capacitação dos recursos internos das firmas (JANK, 1999).

Além disso, inovações de produto e processo podem servir para melhorar o desempenho ambiental das empresas e, ao mesmo tempo, fazer com que estas obtenham vantagens como redução de custos, aumento da produtividade e exploração de novos mercados garantindo-lhes 
assim posições competitivas à frente da concorrência (PORTER E VAN DER LINDE, 1995). Quando se trata das estratégias pro ativas, o meio ambiente é encarado como elemento de competitividade extra-custos. A introdução da gestão ambiental nas empresas se faz com o objetivo inicial de prevenir o impacto ambiental e de antecipação com respeito à evolução da regulamentação - a que Porte (1996) chamou de gestão antecipada de uma legitimidade contestável - e, a seguir, com a finalidade de prospecção e desenvolvimento de novas oportunidades de negócio - no sentido do que Porte \& Van der Linde (1995) consideram como a construção de uma competitividade assegurada pelos investimentos na área ambiental. Este tipo de estratégia corresponde à situação da gestão ambiental nas empresas que, como mencionamos, começa a se desenvolver paulatinamente a partir da década de 80.

\section{CONCLUSÃO}

O resultado da pesquisa mostra que é possível a integração das normas ISO 9000 ( qualidade), ISO 14001(ambiental), OHSAS(segurança) e SA (responsabilidade social). Muitas das empresas vem buscando esta integração de forma isoladas, mas descentralizadas os seus processos de gestão. Quando a empresa visualiza a deve internamente quebrar todas as barreiras dos seus departamento ela poderá ver e integrar as normas. O resultado desta integração é um avanço que leva a empresa a ter vantagem competitiva.

Quando da apresentação das características das quatro normas em uma tabela comparativa, pode entender e visualizar com mais clareza do processo de integração destas normas. O importante desta integração é o dono do capital estar disposto e participativo para que ocorra esta integração.

\section{REFERENCIAS BIBLIOGRÁFICOS}

ABNT, NBR ISO14001: 1996: sistemas de gestão ambiental: especificação e diretrizes para uso. Rio de Janeiro, 1996.

ABNT, ASSOCIAÇÃO BRASILEIRA DE NORMAS TÉCNICAS. NBR ISO9001: 2000: sistemas de gestão da qualidade: requisitos. Rio de Janeiro, 2000.

ANTUNES, Paulo. Cresce a capacidade de compartilhar. Fórum de Líderes, Minas Gerais, n. 6, ano IV, p.1-10. Julho, 2001.

ARANTES, E. Investimento em responsabilidade social e sua relação com o desempenho econômico das empresas. Prêmio Ethos de Respons. Social, 2005.

ARNT, Ricardo. Madeira de Lei. Revista Exame. ano 35.Ed.751.17/10/2001.

BARBIERI, J.C. Gestão ambiental empresarial, São Paulo, Saraiva, 2007.

BABAKRI, K. A. Recycling performance of firms before and after adoption of the ISO 14001 standards. Journal of Cleaner Production, v. 12, p. 633-637, 2004

COLACIOPPO, S. Controle do Ambiente de Trabalho: Riscos Químicos e Saúde do Trabalhador, São Paulo, 2004. 
CORAZZA, R.I. Gestão Ambiental e mudanças da estrutura organizacional, RAE-eletrônica, v. 2, n. 2, jul-dez/2003.

CURKOVIC, S.; SROFE, R.; MELNYK, S. Identifying the factors which affect the decision to attain ISO 14000. Energy, v. 30, n. 88, p. 1387-1407, 2005.

CARVALHO, M. M.; PALADINI, E. P. Gestão da qualidade: teoria e casos. Rio de Janeiro: Campus, 2005. 304p.

CASTRO, R.; OIIVEIRA, $\mathbf{0}$. J. Challenges and difficulties of destination and recycling of used tires in Brazil, 2007.

FAUCHEUX, S.; HAAKE, J.; NICOLAÏ, I. Implications de la mondialisation économique sur La relation environnement-entreprises. Rapport de Recherche: C3ED/DGAD/SRAE n 95285, 1997.

FERRAZ, J. C., Made in Brazil: desafios competitivos para a indústria. Rio de Janeiro/RJ, 1996 Ed. Campus.

FRANCESCHINI, F.; GALETTO, M.; CECCONI, P. A worldwide analysis of ISO 9000 standard diffusion. Benchmarking: an international journal, v. 13, p. 523-541, 2006.

GILL, Antonio Carlos. Como elaborar projetos de pesquisa. São Paulo: Atlas, 1999.

GARVIN, D. A. Managing quality: the strategic and competitive edge. EUA, New York: Harvard Business School, 1988.

GRIEFAHN, M. (1993, July). Initiatives in Lower Saxony to combine the ecology and economy, ecoontrolling, eco-purchasing and EXPO-2000. Proceedings of the Conference 2020 Visions - Britain, Germany and a New Environmental Agenda, London, United Kingdom.

GRAJEW, Oded. Por um mundo mais seguro, Revista exame, Guia da boa cidadania corporativa, 2001 pg. 20-21.

JANK, M. S. Competitividade e globalização, São Paulo: Pioneira, 1999.

KAPLAN, R., NORTON, D.P., Mapas estratégicos - Balance Scorecard: convertendo ativos intangíveis em resultados tangíveis, Rio de Janeiro, Elsevier, 2004.

MAGD, H.; CURRY, A. ISO 9000 and TQM: are they complementary or contradictory to each other? The TQM Magazine, v. 15, n. 4, p. 244-256, 2003.

QUELHAS, L.G. Análise de fatores para gestão de mudanças: Gestão do Conhecimento, Intraempreendedorismo e Engenharia de Resiliencia. XXVI ENEGEP - Fortaleza, CE, Brasil, 9 a 11 de Outubro de 2006.

MCINTOSH, Malcom. et al. Cidadania corporative: estratégias bem sucedidas para empresas responsáveis. Tradução de Bazan Tecnologia e Lingüística. Rio de Janeiro: Qualitymark Ed, 2001.

PORTER, M.E., Estratégia Competitiva: Técnicas para análise de indústrias e da concorrência, 7 ed. Rio de Janeiro, Campus, 1990.

PORTER, M. E.; VAN DER LINDE, C. Toward a new conception of the environment-competition relationship. Journal of Economic Perspectives, v. 8, n. 4, p. 97-118, 1995. 2004.

OLIVEIRA, O. J. (Org.). Gestão da qualidade: tópicos avançados. São Paulo: Thomson Learning,

OLIVEIRA, O. J.; GRAEL, P. F. F. A study on the integration of ISO 9001 and ISO 14001 management systems in a Brazilian furniture company. In: INTERNATIONAL ANNUAL EUROMA CONFERENCE, 14, 2007. Proceedings. 
ROHRICH, S. S.; CUNHA, J. C. A proposição de uma taxonomia para a análise da gestão ambiental no Brasil. Revista de Administração Contemporânea, v. 8, n. 4, p. 86-95, 2004.

SANTOS, F.C.A, JABBOM, C.J.C., Evolução da Gestão Ambiental na empresa: uma Taxonomia integrada a gestão da produção e de recursos humanos, Gestão e Produção, 2006, v.13 pag. 435-448

SLACK, N., CHAMBERS, S., HARLAND, C., HARRISON, A., JOHNSTON, R. Administração da Produção. São Paulo: Atlas, 2002.

SEIFFERT, M. E. B. ISO 14001: Sistemas de gestão ambiental. São Paulo: Atlas, 2008.

SUN, H. Total quality management, ISO 9000 certification and performance improvement. International Journal of Quality and Reliability Management, v. 17, n. 2, p. 168-179, 2000.

VINHA, V. As empresas e o desenvolvimento sustentável: do eco-eficiência à responsabilidade social corporativa. Rio de Janeiro, Elsevier, 2003.

www.immetro.gov.br

www.sai.com

\section{AGRADECIMENTOS}

Ao Programa de pós graduação da Universidade Feevale pelo suporte a esta investigação e pelas excelentes condições de trabalho. 